\title{
Herpes zóster. Actualización y manejo
}

\section{Herpes zoster. Management and treatment update}

\author{
María Gabriela Torres Ordóñez ${ }^{1}$, Dolores Bastard² y Ana Clara Torre ${ }^{3}$
}

\section{RESUMEN}

El herpes zóster es una enfermedad infecciosa producida por el virus de la varicela zóster, caracterizada por la aparición de vesículas que suelen presentarse en una disposición metamérica. Su incidencia se encuentra en aumento y es un motivo de consulta frecuente en la práctica cotidiana. En este artículo se ofrece información actuali- zada acerca de su diagnóstico, tratamiento y prevención, así como sobre otros aspectos controvertidos de su manejo.

Palabras clave: herpes zóster, diagnóstico, tratamiento, hospitalización, complicaciones.

Dermatol. Argent. 2021, 27 (2): 44-52

\section{ABSTRACT}

Herpes zoster is an infectious disease caused by varicella zoster virus, characterized by the development of vesicles, which usually present with a metameric arrangement. Its incidence is increasing and is a frequent reason for consultation in daily practice. This article offers updated information on its diagnosis, treatment and prevention, as well as controversial aspects of the management of this pathology.

Key words: herpes zoster, diagnosis, treatment, hospitalization, complications.

Dermatol. Argent. 2021, 27 (2): 44-52
${ }^{1}$ Médica Becaria

2 Médica Asociada

${ }^{3}$ Médica de Planta

Servicio de Dermatología, Hospital Italiano de Buenos Aires, Ciudad Autónoma de Buenos Aires, Argentina
Contacto de la autora: María Gabriela Torres Ordóñez E-mail: gabriela.torres@hospitalitaliano.org.ar Fecha de trabajo recibido: 24/2/2021 Fecha de trabajo aceptado: 14/6/2021 Conflicto de interés: las autoras declaran que no existe conflicto de interés.

\section{¿QUÉ ES EL HERPES ZÓSTER?}

El virus de la varicela zóster (VVZ) es un virus $\mathrm{ADN}$, bicatenario, cuya transmisión se produce a través de partículas aerosolizadas de las secreciones respiratorias o presentes en las lesiones cutáneas de una persona enferma. Ingresa en el organismo por la mucosa de la vía aérea superior, allí se replica y se disemina a través de la sangre y el sistema reticuloendotelial. Tras un período de incubación de 10 a 21 días, el 90\% de los pacientes susceptibles presentarán un cuadro caracterizado por fiebre y un exantema que comienza con pápulas eritematosas, las cuales luego se transforman en vesículas con un centro umbilicado, después en pústulas y, por último, en costras serohemáticas. El exantema, que suele ser pruriginoso, evoluciona en brotes con el característico polimorfismo lesional, progresa de forma centrífuga y en sentido cefalocaudal, y recibe el nombre de varicela. Una vez resuelta la primoinfección, el virus permanece latente de por vida en los ganglios sensoriales de la raíz dorsal y los nervios craneales ${ }^{1}$.

En condiciones de inmunosenescencia o inmunosupresión, el virus se puede reactivar. Se replica en uno o más ganglios y, más tarde, los viriones se distribuyen de manera antidrómica a lo largo de los nervios sensiti- 
vos. Una vez que alcanzan las terminaciones nerviosas intraepidérmicas y la red neural perifolicular, se produce la replicación viral en la epidermis y en los queratinocitos infundibulares, lo que genera el desarrollo del herpes zóster $(\mathrm{HZ})^{2}$.

Se estima que el $95 \%$ de la población ha sido expuesta al VVZ durante la infancia y que el $30 \%$ de estas personas tienen el riesgo de padecer $\mathrm{HZ}^{3}$. Si bien en la Argentina no se cuenta con datos epidemiológicos, es una enfermedad de observación frecuente en la práctica cotidiana ${ }^{1}$.

\section{¿CUÁLES SON LOS FACTORES DE RIESGO PARA CONTRAER HERPES ZÓSTER?}

El HZ es más frecuente en las mujeres, en los mayores de 60 ańos, en los pacientes inmunosuprimidos (con tratamiento inmunosupresor, radioterapia, VIH/ sida, diabetes mellitus o cáncer) y en quienes tuvieron varicela antes del año de edad $\mathrm{d}^{4,5}$.

\section{¿CUÁL ES LA PRESENTACIÓN CLÍNICA?}

Suele presentar múltiples vesículas agrupadas en ramillete, que asientan sobre una base eritematosa y se disponen en uno o más dermatomas. Los que se afectan con mayor frecuencia, de acuerdo con la bibliografía y nuestra experiencia, son los de localización torácica $(55 \%)$, seguidos por el trigémino $(20 \%)$, los lumbares (13\%), los cervicales (11\%) y los sacros $(2 \%)^{1}$. Las lesiones cutáneas suelen ser unilaterales. En el $80 \%$ de los casos, la erupción es precedida por dolor en el área afectada; un menor número de pacientes pueden referir astenia, decaimiento, fiebre o cefalea ${ }^{1,4}$.

\section{¿CÓMO SE REALIZA EL DIAGNÓSTICO?}

El diagnóstico es clínico. Solo ante dudas diagnósticas (Tabla 1), se sugiere realizar las técnicas de diagnóstico disponibles en la actualidad, entre las que se encuentran el citodiagnóstico de Tzanck, la inmunofluorescencia directa y la prueba de PCR (Tabla $2)^{1,6}$. En nuestra práctica, solemos recurrir a ellas, sobre todo, en los pacientes con un cuadro clínico atípico.

\section{¿CUÁNDO SE DEBE TRATAR A LOS \\ PACIENTES CON HERPES ZÓSTER?}

En la mayoría de las personas inmunocompetentes, el $\mathrm{HZ}$ es una enfermedad autolimitada. Aun así, se recomienda tratar a todos los pacientes con cuadros de menos de 72 horas de evolución, ya que el tratamiento temprano alivia el dolor durante la fase aguda, limita la extensión y la duración de la erupción, previene la neuralgia posherpética y disminuye la transmisión viral ${ }^{1,2,7,8}$.

Ausencia de fase prodrómica típica
Compromiso de más de un dermatoma o que no respeta la línea
media
Afección en regiones corporales por fuera del tórax
Curso temporal y lesiones cutáneas atípicas
Antecedentes de HZ
Antecedentes de vacunación contra el virus de la varicela zóster
TABLA 1: Indicaciones para la solicitud de estudios confirmatorios en el
diagnóstico del herpes zóster ${ }^{1,2}$.

\begin{tabular}{|c|c|c|}
\hline Método & $\begin{array}{c}\text { Sensibilidad(S) } \\
\text { yespecificidad (E) }\end{array}$ & Características \\
\hline$P C R$ & $\begin{array}{l}95 \% \mathrm{~S} \\
100 \% \mathrm{E}\end{array}$ & $\begin{array}{l}\text { Detecta el ADN del virus en las lesio- } \\
\text { nes cutáneas en todos los estadios, } \\
\text { el } L C R \text {, la sangre, los tejidos y en } \\
\text { otros líquidos corporales. } \\
\text { La muestra de la piel se puede tomar } \\
\text { por hisopado o biopsia. } \\
\text { El resultado demora } 24 \text { a } 48 \text { horas. }\end{array}$ \\
\hline IFD & $\begin{array}{l}82 \% \mathrm{~S} \\
76 \% \mathrm{E}\end{array}$ & $\begin{array}{l}\text { Detecta glucoproteínas virales en } \\
\text { las lesiones cutáneas. La toma de } \\
\text { muestra de la piel se debe hacer por } \\
\text { hisopado del fondo de las vesículas. El } \\
\text { resultado demora } 24 \text { horas. }\end{array}$ \\
\hline $\begin{array}{l}\text { Cultivo } \\
\text { viral }\end{array}$ & $\begin{array}{l}30-70 \% \mathrm{~S} \\
100 \% \mathrm{E}\end{array}$ & $\begin{array}{l}\text { Permite el aislamiento del virus de los } \\
\text { tejidos afectados. Su sensibilidad es } \\
\text { mayor cuando la muestra se obtiene } \\
\text { por aspirado del líquido de las vesículas } \\
\text { en una jeringa con un medio de trans- } \\
\text { porte viral y se procesa de inmediato. } \\
\text { El resultado demora de } 3 \text { a } 14 \text { días. }\end{array}$ \\
\hline $\begin{array}{l}\text { Citodiag- } \\
\text { nóstico } \\
\text { de } \\
\text { Tzanck }\end{array}$ & $\begin{array}{l}50-80 \% \text { S } \\
\text { No permite } \\
\text { distinguirher- } \\
\text { pes simple de } \\
\text { herpes zóster }\end{array}$ & $\begin{array}{l}\text { Detecta la presencia de células gigan- } \\
\text { tes multinucleadas en las lesiones } \\
\text { cutáneas. } \\
\text { La toma de muestra de la piel se realiza } \\
\text { por raspado del fondo de las lesiones. } \\
\text { El resultado tiene una demora variable. }\end{array}$ \\
\hline $\begin{array}{l}\text { Pruebas } \\
\text { serológi- } \\
\text { cas }\end{array}$ & $\begin{array}{l}\text { No es un méto- } \\
\text { do sensible ni } \\
\text { específico }\end{array}$ & $\begin{array}{l}\text { Todos los pacientes con HZ son } \\
\text { seropositivos para VVZ. Si bien al- } \\
\text { gunos muestran una elevación del } \\
\text { título de anticuerpos durante el } \\
\text { episodio de } \mathrm{HZ} \text {, esto no permite el } \\
\text { diagnóstico, por lo que este méto- } \\
\text { do no se recomienda. }\end{array}$ \\
\hline
\end{tabular}

TABLA 2: Estudios para el diagnóstico etiológico del herpes zóster ${ }^{4,6}$. 


\section{¿CUÁL ES EL MANEJO APROPIADO SI EL PACIENTE CONSULTA DESPUÉS DE 72 HORAS DEL COMIENZO DEL CUADRO?}

El beneficio de tratar a los pacientes inmunocompetentes después de las 72 horas del comienzo del cuadro se desconoce. Diversos autores, entre los que nos contamos, lo recomiendan en los casos seńalados en la Tabla $3^{1,2}$.

Pacientes mayores de 50 años
Inmunosuprimidos
Enfermedades cutáneas previas graves (p. ej., dermatitis atópica,
pénfigo vulgar)
Niños 0 adolescentes en tratamiento prolongado con corticosteroi-
des o ácido salicílico
Compromiso de la cabeza o el cuello
HZ diseminado
Lesiones hemorrágicas o necróticas
Vesículas aberrantes o lesiones satélites
Compromiso de las mucosas
Dolor moderado a intenso
TABLA 3: Indicaciones del tratamiento antiviral en los pacientes con herpes
zóster de más de 72 horas de evolución ${ }^{1,2}$.

\section{¿QUÉ TRATAMIENTO SE DEBE INDICAR?}

El tratamiento de elección son los análogos de los nucleósidos como el aciclovir (oral o intravenoso), el valaciclovir, el famciclovir y la brivudina, que inhiben la replicación de los virus herpes porque interfieren en la ADN polimerasa de estos. No hay evidencia concluyente en cuanto a la superioridad del valaciclovir $(1 \mathrm{~g} / 8$ horas), el famciclovir (500 mg/8 horas) y la brivudina (125 mg/día) sobre el aciclovir oral (800 mg 5 veces/ día). Algunos autores observaron que el valaciclovir es más eficaz que el aciclovir para reducir la aparición de la neuralgia posherpética (19\% contra $27 \%$, respectivamente $)^{4}$. Sin embargo, se debe considerar que, de estos fármacos, el aciclovir es el menos costoso. Es el antiviral más utilizado en nuestra práctica clínica.

$\mathrm{El}$ aciclovir, el famciclovir y el valaciclovir deben ajustarse de acuerdo con la función renal. Si bien la brivudina tiene la mejor posología en comparación con los otros antivirales, ya que se indica una vez por día, hay que tener en cuenta que está contraindicada en los pacientes inmunosuprimidos o en los que hayan recibido, en el último mes, fármacos con 5-fluoropirimidina, como el 5-fluorouracilo o la flucitosina, debido a la posibilidad de interacciones medicamentosas graves ${ }^{2}$. En la Argentina, no contamos con el famciclovir ni con la brivudina. Algunos autores recomiendan una duración del tratamiento de 7 días, pero otros opinan que debe continuar hasta que el paciente no presente lesiones activas (vesículas). Esta última suele ser nuestra conducta en los pacientes inmunosuprimidos. Si después de 21 días las vesículas persisten, se debe considerar la posibilidad de resistencia al aciclovir ${ }^{1}$.

\section{¿CUÁNDO SE DEBE HOSPITALIZAR E INDICAR TRATAMIENTO INTRAVENOSO?}

El HZ requiere hospitalización en un 3\% de los ca$\operatorname{sos}^{9}$. Esto es más frecuente en los pacientes con dermatitis atópica, psoriasis, pénfigo, micosis fungoide, dermatomiositis, esclerodermia y lupus. Se han identificado como predictores de hospitalización el sexo femenino y el uso prolongado de corticosteroides sistémicos ${ }^{10}$.

En la Tabla 4 se especifican las indicaciones del tratamiento intravenoso con aciclovir. La dosis recomendada es de $10 \mathrm{mg} / \mathrm{kg} / 8$ horas, durante 7 a 10 días $^{1}$. En el caso de afectación visceral, se sugiere aumentar la dosis a $15 \mathrm{mg} / \mathrm{kg} / 8$ horas durante 21 días $^{2}$.

Inmunosuprimidos (cáncer, enfermedades oncohematológicas, VIH, trasplante de médula ósea o de órgano sólido, fármacos inmunosupresores)

Enfermedades cutáneas graves predisponentes para la diseminación (dermatitis atópica, pénfigo vulgar, etc.)

Compromiso de la cabeza o el cuello

HZ ótico u oftálmico

$\mathrm{HZ}$ diseminado

Compromiso visceral

Dolor prodrómico o dolor agudo intenso

TABLA 4: Indicaciones de hospitalización y tratamiento con aciclovir intravenoso $0^{1,2}$.

\section{¿SE DEBE AISLAR A LOS PACIENTES CON HERPES ZÓSTER?}

En el HZ, el VVZ se transmite por contacto directo con las vesículas, mientras que en las formas diseminadas de la enfermedad, también se dispersa mediante las secreciones respiratorias. Por este motivo, los Centers for Disease Control and Prevention (CDC) de Estados Unidos recomiendan el aislamiento de contacto en el HZ y el aislamiento de contacto y por gotas de todos los pacientes con la forma diseminada de la enfermedad, ya sean inmunosuprimidos o inmunocompetentes ${ }^{8,11}$.

Se sugiere otorgar licencia de trabajo a todos los pacientes con varicela o $\mathrm{HZ}$ diseminado y a todos los individuos inmunosuprimidos con HZ. Se recomienda la reincorporación laboral luego de que todas las lesiones se encuentren en estadio de costra (en general, después de 5 días del inicio de los síntomas). 
Diversos autores opinan que los pacientes sanos con $\mathrm{HZ}$ dermatomérico pueden continuar sus tareas si el área afectada está cubierta de manera estéril y bajo la ropa. Los pacientes no deberían estar en contacto con las personas de riesgo (inmunosuprimidos, embarazadas y menores de un año) hasta que todas las lesiones hayan formado una costra ${ }^{8}$.

\section{¿CUÁLES SON CONSIDERADAS SITUACIONES ESPECIALES EN EL HERPES ZÓSTER?}

Durante el embarazo: el manejo es controvertido. $\mathrm{Si}$ bien algunos autores proponen realizar tratamiento a todas las pacientes con el objetivo de alcanzar una curación rápida y un adecuado manejo del dolor, otros sugieren indicarlo a aquellas con manifestaciones cutáneas floridas (más de 50 lesiones), neuritis aguda o factores de riesgo para complicaciones (Tabla 5) ${ }^{8,12}$. Por otro lado, hasta la fecha, la Food and Drug Administration (FDA) y la Administración Nacional de Medicamentos, Alimentos y Tecnología Médica de la República Argentina (ANMAT) no han aprobado el uso del aciclovir en el embarazo y no se han hecho estudios controlados en seres humanos que permitan evaluar las consecuencias de este fármaco para el feto. Sin embargo, hay estudios retrospectivos que no evidenciaron riesgos, por lo cual se lo considera de categoría B. Por lo tanto, el aciclovir sería el fármaco de elección ${ }^{13}$.

En los nińos: la varicela es una enfermedad frecuente en la infancia, pero los episodios de $\mathrm{HZ}$ son infrecuentes en los menores de 10 años. La incidencia de $\mathrm{HZ}$ en la niñez varía entre 0,2 y 0,74 casos cada 1000 nińos por año. Puede ocurrir en aquellos que tuvieron varicela $\mathrm{o}$, de forma menos frecuente, en los que fueron vacunados, dado que se trata de una vacuna elaborada con virus vivos ${ }^{14-16}$. En los niños, el síntoma más común es el prurito. El dolor, en comparación con los adultos, es excepcional ${ }^{14}$. Según un estudio realizado por Aktaş et ál., las localizaciones más frecuentes en los mayores de 10 años fueron la torácica (como en los adultos) y la lumbar, mientras que en los niños menores, los dermatomas afectados con mayor asiduidad fueron los cervicales, los sacros y el trigémino. Si bien suele creerse que el $\mathrm{HZ}$ está relacionado con la inmunosupresión, se observó que el $80 \%$ de los niños afectados son inmunocompetentes. En los niños sin comorbilidades, el $\mathrm{HZ}$ tiene un curso leve a moderado y suele resolverse en 1 a 3 semanas $^{14}$. En la actualidad, en ausencia de factores de riesgo para complicaciones (Tabla 5), algunos autores sugieren no indicar tratamiento antiviral a los nińos con HZ. Por el contrario, ante la presencia de estos, se recomienda el tratamiento específico (Tabla 6) ${ }^{17-19}$. Aunque falta evidencia sobre

\begin{tabular}{l}
\hline Edad avanzada \\
Inmunosupresión \\
\hline Compromiso de la cabeza o el cuello \\
\hline Presencia de lesiones hemorrágicas o necróticas \\
\hline Afectación multimetamérica \\
\hline Vesículas aberrantes o lesiones satélites \\
\hline Compromiso de las mucosas \\
\hline HZ diseminado \\
\hline Afectación visceral o del SNC (incluida la vasculitis) \\
\hline Dolor prodrómico o dolor agudo intenso \\
\hline TABLA 5: Factores de riesgo para el desarrollo de complicaciones por \\
herpes zóster ${ }^{1,2}$.
\end{tabular}

\begin{tabular}{l|l} 
& Vía intravenosa: \\
& $<1$ año: $30 \mathrm{mg} / \mathrm{kg} /$ día, cada 8 horas, $7-10$ días \\
& $\geq 1$ año: $1500 \mathrm{mg} / \mathrm{m}^{2} /$ día $030 \mathrm{mg} / \mathrm{kg} /$ día cada \\
& 8 horas, $7-10 \mathrm{días}$ \\
& Algunos autores proponen: \\
& $<12$ años: $60 \mathrm{mg} / \mathrm{kg} /$ día cada 8 horas, $7-10$ días \\
& $\geq 12$ años: $30 \mathrm{mg} / \mathrm{kg} /$ día cada 8 horas, $7-10$ días \\
Inmuno- & Vía oral: \\
competente & Entre 2 y 12 años: $800 \mathrm{mg}, 5$ veces por día, $5-7$ días \\
& Dosis máxima: $80 \mathrm{mg} / \mathrm{kg} /$ día en 5 dosis
\end{tabular}

la seguridad del uso del aciclovir en los niños, diversos autores proponen que, como se lo ha utilizado durante años en pediatría de manera segura, sería el fármaco de elección en este grupo etario ${ }^{19,20}$.

HZ ótico: se presenta con afección del oído interno, medio o externo (Foto 1). Se caracteriza por una otalgia grave, que puede preceder a la erupción vesiculosa como fase prodrómica o ser la única manifestación del cuadro (zóster sin herpes) ${ }^{21}$. Se denomina síndrome de Ramsay-Hunt al HZ ótico asociado a parálisis facial periférica aguda, otalgia, compromiso de la membrana timpánica y, en ocasiones, de los dos tercios anteriores de la lengua o el velo del paladar. Esto se produce por la reactivación del VVZ en el ganglio geniculado (formación situada en el primer codo del VII par craneal) y la afectación de los pares craneales VII y VIII. Las complicaciones de este cuadro incluyen vértigo, acúfenos, disgeusia, hipoacusia 
neurosensorial aguda unilateral, osteonecrosis, náuseas y vómitos ${ }^{2,22,23}$. El tratamiento de los pacientes con este síndrome debe ser interdisciplinario, en conjunto con un otorrinolaringólogo. Se recomienda la asociación de aciclovir intravenoso y corticosteroides sistémicos (meprednisona $1 \mathrm{mg} / \mathrm{kg} /$ día por 10 días), ya que la terapia combinada mejora la evolución del dolor y la parálisis facial ${ }^{2,23-25}$.

HZ oftálmico: se produce por el compromiso de la rama oftálmica del nervio trigémino, la cual tiene, a su vez, tres ramificaciones principales: lagrimal, frontal y nasociliar. Esta última inerva el globo ocular y la punta nasal. La afectación de esta rama suele evidenciarse con compromiso en la punta de la nariz, lo cual se denomina signo de Hutchinson ${ }^{2,26}$. En el 60\% de los pacientes, este se manifiesta con vesículas agrupadas en la piel del área afectada. En los casos restantes, se puede asociar a queratitis (la más frecuente), conjuntivitis, escleritis, retracción palpebral, parálisis oculomotora, glaucoma, neuritis óptica, ptosis paralítica y necrosis retiniana aguda ${ }^{2,27}$. El tratamiento de estos pacientes se debe realizar de forma interdisciplinaria en conjunto con el servicio de oftalmología ${ }^{28}$. Si bien la duración recomendada del antiviral es de 7 a 10 días, dado que el VVZ puede persistir en la córnea hasta un mes, en los pacientes de edad avanzada o inmunosuprimidos se suele prolongar el tratamiento hasta la desaparición de las lesiones ${ }^{26}$.

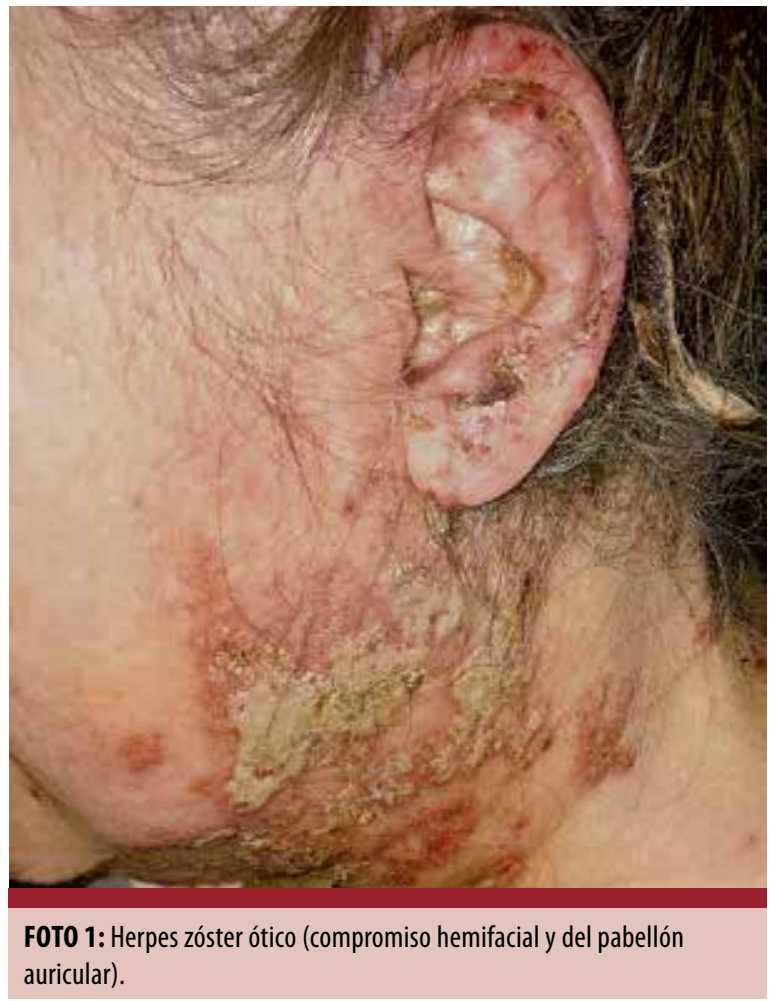

HZ múltiple y HZ diseminado: el HZ múltiple se define como la presencia de lesiones típicas que comprometen dos o más dermatomas no contiguos ${ }^{29}$. Se denomina $\mathrm{HZ}$ diseminado cuando hay compromiso de más de dos dermatomas contiguos o distantes, más de 20 vesículas por fuera del dermatoma inicial o compromiso visceral (Fotos 2 y 3$)^{30}$. Ambos son cuadros graves.

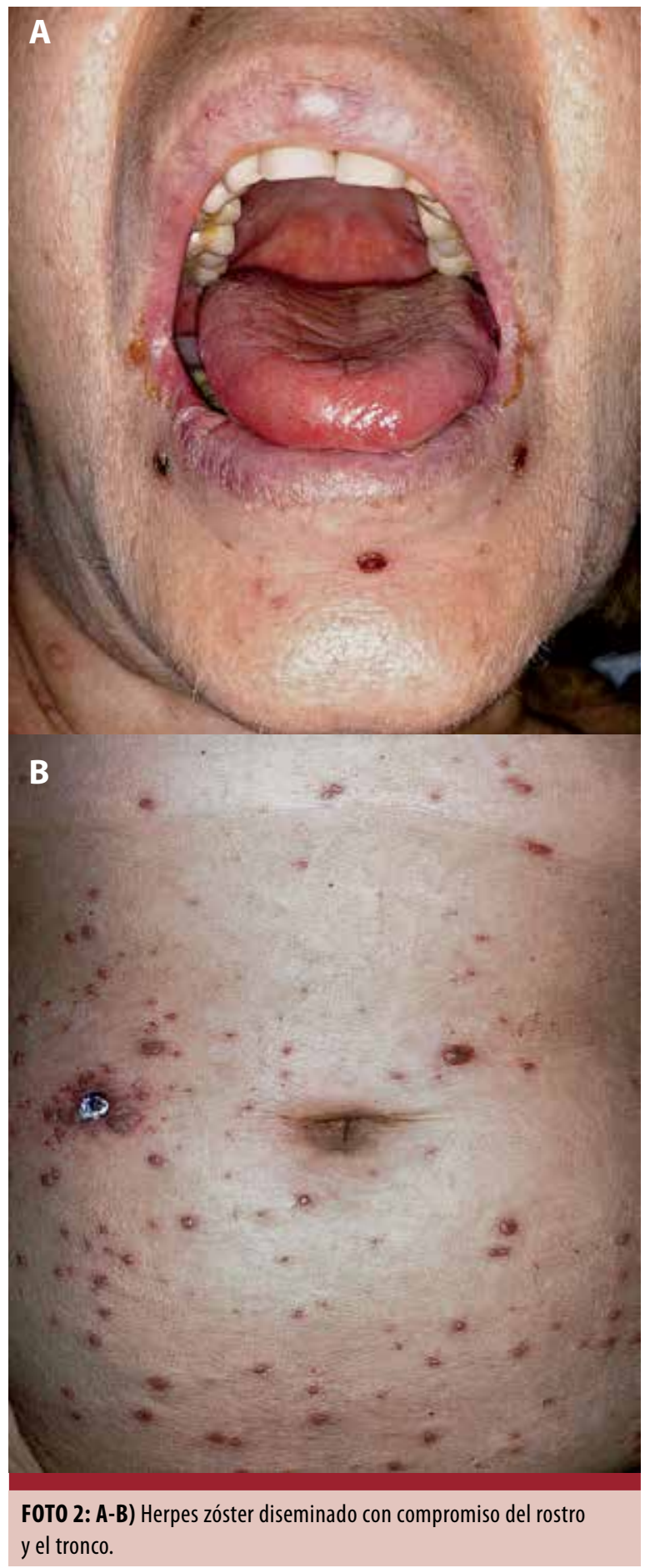




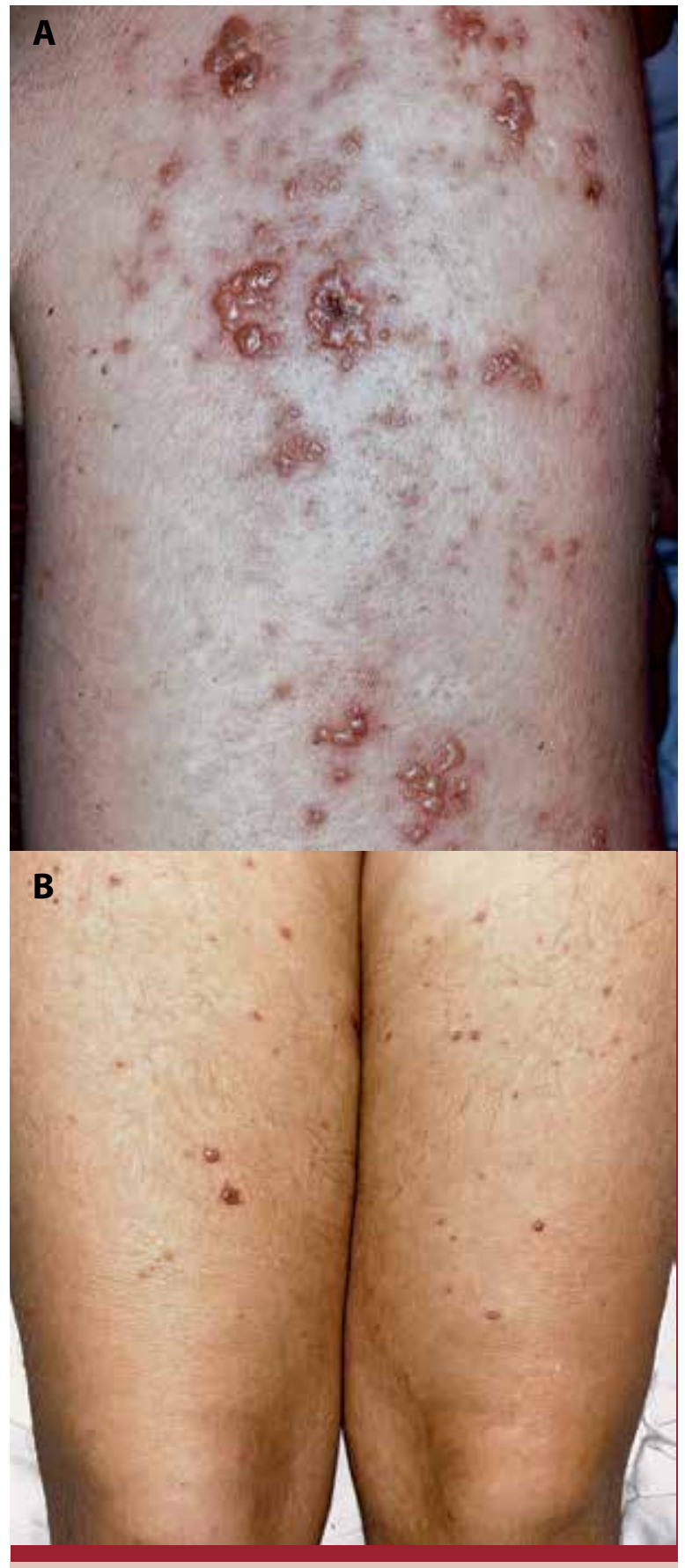

F0T0 3: A-B) Herpes zóster diseminado con compromiso de los miembros.

\section{¿CUÁLES SON LAS POSIBLES}

\section{COMPLICACIONES DEL HERPES ZÓSTER?}

La complicación más frecuente es la neuralgia posherpética. Esta se define como el dolor neuropático que persiste más allá de los 3 meses posteriores al diagnóstico del $\mathrm{HZ}$ y tiene una incidencia del 10-18\%. Es infrecuente en los menores de 40 años y el riesgo aumenta con la edad ${ }^{1}$. Otras complicaciones son la sobreinfección bacteriana (casi siempre por Staphylococcus aureus y, menos a menudo, por estreptococo betahemolítico del grupo A), la parálisis facial periférica, la disfunción vestibular, el com- promiso visceral (neumonitis, hepatitis, necrosis retiniana aguda, artritis, miocarditis, pericarditis, meningitis aséptica, meningoencefalitis, mielitis transversa, vasculopatía multifocal) y las pérdidas auditivas y visuales ${ }^{4,31,32}$.

\section{¿CUÁLES SON LOS ANALGÉSICOS MÁS RECOMENDADOS CONTRA EL DOLOR AGUDO?}

Más del 95\% de los pacientes presentan dolor agudo asociado al $\mathrm{HZ}$ y en el $60-70 \%$ de los casos, este persiste luego de un mes del episodio. La intensidad del dolor debe evaluarse de forma objetiva, para lo cual se recomienda utilizar algunas de las escalas validadas (p. ej., la escala analógica visual) ${ }^{1}$.

El dolor puede ser neuropático o nociceptivo. Es muy importante comprender qué tipo de dolor tiene el paciente a fin de brindarle el tratamiento adecuado. En el dolor nociceptivo, se recomienda indicar analgésicos no opioides como el paracetamol (1 g/12 horas). Si el paciente continúa con dolor, se sugiere agregar un opioide débil como el tramadol ( $50 \mathrm{mg} / 6$ horas) y, en el caso de que no se observe mejoría, rotar a un opioide fuerte ${ }^{1}$. En el dolor neuropático, es conveniente iniciar el tratamiento con analgésicos no opioides y opioides débiles, junto con gabapentina o pregabalina. Una vez que se alcanza una adecuada respuesta terapéutica, se debe discontinuar de forma paulatina en primer lugar el opioide y, luego, el analgésico no opioide ${ }^{1}$ La dosis de gabapentina recomendada es de $900 \mathrm{mg} /$ día, pero se puede aumentar hasta $1800 \mathrm{mg} /$ día si es necesario. La dosis de pregabalina es de 150 a 600 $\mathrm{mg} / \mathrm{dí}$. En los adultos mayores, la dosis inicial debe ser la mitad de la dosis sugerida y se debe aumentar de forma paulatina (dosis-respuesta), dado que puede ocasionar mareos e inestabilidad. En los casos refractarios, se recomienda interconsultar con un especialista en dolor ${ }^{1}$.

\section{¿CUÁLES SON LOS ANALGÉSICOS MÁS RECOMENDADOS PARA LA NEURALGIA POSHERPÉTICA?}

Se recomienda, en primer lugar, la pregabalina y, en segundo lugar, la gabapentina (en dosis similares a las utilizadas en el dolor agudo). Si con estos fármacos no se logra un buen manejo del dolor, se pueden adicionar antidepresivos tricíclicos como la amitriptilina (10 a 25 $\mathrm{mg} / \mathrm{día})$. Cuando no sea posible indicar analgésicos por vía oral, se pueden utilizar parches de capsaicina al 8\%, cuyo principal efecto adverso es la sensación de quemazón en el sitio de aplicación al inicio del tratamiento. El enfriamiento de la zona, antes de la colocación del parche, suele disminuir ese efecto y genera una mayor adherencia terapéutica. Como segunda opción de tratamiento tópico, se recomienda la lidocaína al 5\%33. 


\section{¿SE RECOMIENDA EL USO DE \\ CORTICOSTEROIDES SISTÉMICOS?}

El uso de corticosteroides sistémicos en el manejo del HZ es controvertido. Pueden ser útiles en algunos casos de neuralgia aguda moderada a intensa, pero no son efectivos para evitar la neuralgia posherpética. En estos casos, se utilizan dosis de $60 \mathrm{mg} /$ día de meprednisona y se sugiere un descenso rápido hasta su suspensión al cabo de 10 a 14 días ${ }^{4,32}$. Por otro lado, están indicados en el manejo del HZ oftálmico con compromiso retiniano y en el síndrome de Ramsay-Hunt ${ }^{1}$.

\section{¿DEBO REALIZAR LA PESQUISA DE} ENFERMEDADES SUBYACENTES?

En los pacientes adultos menores de 50 años, se aconseja la realización de pruebas serológicas para el
VIH. Los expertos no recomiendan la búsqueda de neoplasias ocultas ${ }^{1,4}$.

\section{¿EL HERPES ZÓSTER PUEDE RECURRIR?}

Se ha observado que $0,4-15 \%$ de los pacientes que han tenido $\mathrm{HZ}$ pueden presentar un nuevo episodio a lo largo de la vida ${ }^{9}$. La recurrencia suele darse después de los 8 años del primer evento. El riesgo parece ser mayor en las mujeres, en las personas de entre 21 y 50 años y en los inmunosuprimidos ${ }^{34}$.

\section{¿QUÉ VACUNAS HAY PARA LA PREVENCIÓN DEL HERPES ZÓSTER?}

Se cuenta con dos vacunas para la prevención del HZ. En la Tabla 7 se resume la información sobre su composición, eficacia, indicaciones y contraindica-

\begin{tabular}{|c|c|c|}
\hline Vacuna & Zostavax $^{\mathbb{R}}$ & Shingrix ${ }^{\mathbb{R}}$ \\
\hline Aprobación de la FDA & Año 2006 & Año 2017 \\
\hline Aprobación de la ANMAT & Año 2013 & No \\
\hline Composición & Virus vivos atenuados & $\begin{array}{l}\text { Subunidad inactivada del VVZ, compuesta por la } \\
\text { glucoproteína Ey ASO1B como adyuvante }\end{array}$ \\
\hline Dosis & $\begin{array}{l}\text { Única dosis } \\
\text { Aplicación por vía subcutánea }\end{array}$ & $\begin{array}{l}\text { Dos dosis separadas por } 2 \text { a } 6 \text { meses } \\
\text { Aplicación por vía intramuscular }\end{array}$ \\
\hline Eficacia & $\begin{array}{l}\text { Prevención de } \mathrm{HZ} \text { : } \\
\text { - } 70 \% \text { de } 50 \text { a } 59 \text { años } \\
\text { - } 64 \% \text { de } 60 \text { a } 69 \text { años } \\
\text { - 38\% en mayores de } 70 \text { años } \\
\text { Prevención de la neuralgia posherpética: } \\
65 \text { a } 66,8 \% \\
\text { Protección limitada más allá de los } 5 \text { años }\end{array}$ & $\begin{array}{l}\text { Prevención de HZ: } \\
90 \% \text { de } 50 \text { a } 69 \text { años } \\
\text { Prevención de la neuralgia posherpética: } \\
90 \% \\
\text { Protección más allá de los } 5 \text { años }\end{array}$ \\
\hline Indicaciones & $\begin{array}{l}\text { Mayores de } 60 \text { años (se recomienda la vacunación antes de } \\
\text { los } 70 \text { años) sin comorbilidades } \\
\text { Mayores de } 50 \text { años cuyas comorbilidades y antecedentes } \\
\text { los hagan más vulnerables a la enfermedad (Tabla 8) }\end{array}$ & Mayores de 50 años ${ }^{* *}$ \\
\hline Contraindicaciones & $\begin{array}{l}\text { Hipersensibilidad a cualquiera de sus componentes } \\
\text { Inmunosupresión* } \\
\text { Tuberculosis activa sin tratamiento } \\
\text { Embarazo }\end{array}$ & $\begin{array}{l}\text { Hipersensibilidad a cualquiera de sus componentes. } \\
\text { Inmunosupresión*** } \\
\text { No hay datos sobre su uso en el embarazo o la lactan- } \\
\text { cia, por lo que se sugiere postergar la vacunación en } \\
\text { estos casos }\end{array}$ \\
\hline $\begin{array}{l}\text { TABLA 7: Características } \\
\text { *Se puede aplicar a pacientes que } \\
* \text { * Sepuede aplicar a pacientes que } \\
* * * \text { Dado que los pacientes inmun }\end{array}$ & 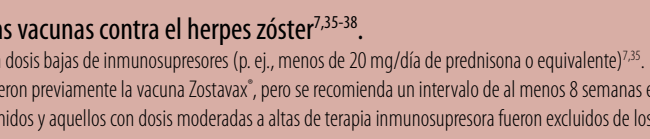 & $\begin{array}{l}\text { bass? } \\
\text { sd efeficacia, no se puede realizar una recomendación en este grupo?'? }\end{array}$ \\
\hline
\end{tabular}


ciones. Ambas pueden administrarse a personas que ya padecieron HZ. Se desconoce cuál es el momento más oportuno para vacunar en estos casos. Las recomendaciones de los expertos sugieren esperar entre 1 y 5 años desde el último episodio de HZ. No se recomienda realizar la pesquisa (anamnesis o pruebas de laboratorio) de evidencia de infección previa por $\mathrm{VVZ}^{7,35}$.

\section{¿SE PUEDE INDICAR ANTIVIRALES PARA \\ LA PREVENCIÓN DEL HERPES ZÓSTER?}

Se recomiendan los antivirales para prevenir el $\mathrm{HZ}$ en los receptores de trasplantes alogénicos de células madre de sangre periférica o en los pacientes medicados con bortezomib, que no pueden recibir la vacuna inactivada. Se puede utilizar aciclovir oral en dosis bajas (400-800 mg/día), valaciclovir ( 250 o $500 \mathrm{mg} /$ día) o famciclovir $(500 \mathrm{mg} / \mathrm{día})^{4}$.

\section{BIBLIOGRAFÍA}

1. Gross GE, Eisert L, Doerr HW, Fickenscher $\mathrm{H}$, et ál. S2k guidelines for the diagnosis and treatment of herpes zoster and postherpetic neuralgia. J Dtsch Dermatol Ges. 2020;18:55-78.

2. Werner RN, Nikkels $A F$, Marinović $B$, Schäfer $M$, et ál. European consensus-based (S2k) Guideline on the Management of Herpes Zoster - guided by the European Dermatology Forum (EDF) in cooperation with the European Academy of Dermatology and Venereology (EADV), Part 1: Diagnosis. J Eur Acad Dermatol Venereol. 2017;31:9-19.

3. Dayan RR, Peleg R. Herpes zoster -typical and atypical presentations. Postgrad Med. 2017;129:567-571.

4. Schmader K. Herpes zoster. Ann Intern Med. 2018;169:19-31.

5. Chen SY, Suaya JA, Li Q, Galindo CM, et ál. Incidence of herpes zoster in patients with altered immune function. Infection. 2014;42:325-334.

6. Bianchi M, Santiso G, Lehmann E, Walker LG, et ál. Utilidad del citodiagnóstico de Tzanck en un hospital de enfermedades infecciosas de la ciudad de Buenos Aires. Dermatol Argent. 2012;18:42-46.

7. Dooling KL, Guo A, Patel M, Lee GM, et ál. Recommendations of the Advisory Committee on Immunization Practices for Use of Herpes Zoster Vaccines. MMWR Morb Mortal Wkly Rep. 2018;67:103-108.

8. Weber JD, Hirsch MS, Mitty J. Prevention and control of varicellazoster virus in hospitals. [en línea]. UpToDate, 14 de enero de 2020. Disponible en: https://www.uptodate.com/contents/preventionand-control-of-varicella-zoster-virus-in-hospitals. [Consulta: enero 2021].

9. Ahronowitz I, Fox LP. Herpes zoster in hospitalized adults: Practice gaps, new evidence, and remaining questions. J Am Acad Dermatol. 2018;78:223-230.

10. Chovatiya R, Silverberg J. Association of herpes zoster and chronic inflammatory skin disease in US in patients. J Am Acad Dermatol. 2020;1-10.

11. Preventing Varicella-Zoster Virus (VZV) Transmission from Herpes Zoster in Healthcare Settings, [en línea]. CDC, 14 de agosto de 2019. Disponible en: https://www.cdc.gov/shingles/hcp/hcsettings.html [Consulta: enero 2021].

12. Müllegger RR, Häring NS, Glatz M. Skin infections in pregnancy. Clin Dermatol. 2016;34:368-377.

13. Schafer R, Davis M, Phillippi JC. Herpes zoster in pregnancy. J Midwifery Womens Health. 2019;64:230-235.

14. Aktaş H, Erdal SA, Güvenç U. Herpes zoster in children: evaluation

\section{Depresión}

Alcoholismo

Enfermedad inflamatoria intestinal

Psoriasis 0 artritis psoriásica

Enfermedad reumatológica, en especial en aquellos en plan de tratamiento con anti-TNF y tofacitinib ( 2 a 4 semanas antes de iniciarlos)

Asma y enfermedad pulmonar obstructiva crónica con corticosteroides inhalatorios

Asplenia funcional y anatómica

Deficiencia crónica del complemento

Insuficiencia cardíaca congestiva en clase funcional III-IV

Enfermedad hepática crónica

Insuficiencia renal crónica terminal

Plan de trasplante de órgano sólido (2 a 4 semanas antes)

TABLA 8: Condiciones en las cuales se debe considerar la vacunación en los mayores de 50 años ${ }^{37}$.

of the sixty cases. Dermatol Ther. 2019;32:1-5.

15. Feder HM, Hoss DM. Herpes zoster in otherwise healthy children. Pediatr Infect Dis J. 2004;23:451-457.

16. Leung AKC, Robson WLM, Leong AG. Herpes zoster in childhood. J Pediatr Health Care. 2006;20:300-303.

17. Comité de Medicamentos. Pediamecum. Aciclovir. Aeped. [en línea], 8 de abril de 2015. Disponible en: https://www.aeped.es/comitemedicamentos/pediamecum/aciclovir. [Consulta: enero 2021].

18. Acyclovir (systemic): Pediatric drug information, [en línea], UpToDate. Disponible en: https://www.uptodate.com/contents/ acyclovir-systemic-pediatric-drug-information?search=aciclovir [Consulta: enero 2021].

19. Agentes antivirales. CIME [en línea], 1 de marzo de 2001. Disponible en: https://www.garrahan.gov.ar/PDFS/cime/ marzo01.pdf [Consulta: enero 2021].

20. Kakourou T, Theodoridou M, Mostrou, Syriopoulou V, et ál. Herpes zoster in children. J Am Acad Dermatol. 1998;39:207-210.

21. Lee HL, Yeo M, Choi GH, Lee JY, et ál. Clinical characteristics of headache or facial pain prior to the development of acute herpes zoster of the head. Clin Neurol Neurosurg. 2017;152:90-94.

22. Wagner $G$, Klinge H, Sachse M. Ramsay Hunt syndrome. J Dtsch Dermatol Ges. 2012;10:238-244.

23. Jeon Y, Lee H. Ramsay Hunt syndrome. J Dent Anesth Pain Med. 2018;18:333-337.

24. Orgaz Gallego MP, Curbelo del Bosco JM, Tricio Armero MA, Pérez Sánchez S. Un paciente con síndrome de Ramsay Hunt. A propósito de un caso. Rev Clin Med Fam. 2016;9:119-122.

25. Murakami S, Hato N, Horiuchi J, Honda N, et ál. Treatment of Ramsay Hunt syndrome with acyclovir-prednisone: significance of early diagnosis and treatment. Ann Neurol. 1997;41:353-357.

26. Palmerín Donoso A, Tejero Mas M, Buitrago Ramírez F. Herpes zóster oftálmico. Atención Primaria. 2019;51:123-124.

27. Seng Boon HK, You Siang N, Jalaluddin J, Norlina R. Herpes zoster keratouveitis with hypopyon and hyphema. Taiwan J Ophthalmol. 2020;10:54-57.

28. Werner RN, Nikkels AF, Marinovic $M$, Schäfer $M$, et ál. European consensus-based (S2k) Guideline on the Management of Herpes Zoster - guided by the European Dermatology Forum (EDF) in cooperation with the European Academy of Dermatology and Venereology (EADV), Part 2: Treatment. J Eur Acad Dermatol Venereol. 2017;31:20-29.

29. Nam KH, Jung ES, Park J, Yun SK. A clinical and etiological study 
of herpes zoster multiplex. [en línea]. J Am Acad Dermatol, 6 de octubre de 2020. Disponible en: https:// doi.org/10.1016/j. jaad.2020.10.011. [Consulta: enero 2021].

30. Bollea Garlatti ML, Bollea Garlatti LA, Vacas AS, Torre AC. Características clínicas y evolutivas de una población con herpes zoster diseminado: un estudio de cohorte retrospectivo. Actas Dermosifiliogr 2017;108:145-152.

31. Shingles Home. For Health Care Professionals. Clinical Overview [en línea] CDC. 31 de mayo de 2020. Disponible en: https://www.cdc. gov/shingles/hcp/clinical-overview.html. [Consulta: enero 2021].

32. Cohen JL. Clinical practice: herpes zoster. $N$ Engl J Med. 2013;369:255-263.

33. Lara Solares A, Mayoral Rojas V, Guillén Núñez MR, Villafaña Tello JJS, et ál. Consenso multidisciplinario de diagnóstico y tratamiento del dolor neuropático periférico y localizado en México. Gac Med Mex. 2019;155:428-435.

34. Qian J, Macartney K, Heywood AE, Sheridan S, et ál. Risk of recurrent herpes zoster in a population-based cohort study of older adults. [en línea]. J Am Acad Dermatol, 29 de junio de 2020. Disponible en: https://doi.org/10.1016/j.jaad.2020.06.1013. [Consulta: enero 2021].

35. Cunningham AL, Lal H, Kovac M, Chlibek R, et ál. Efficacy of the herpes zoster subunit vaccine in adults 70 years of age or older. $N$ Engl J Med. 2016;75:1019-1032.

36. Oxman MN, Levin MJ, Johnson GR, Schmader KE, Feldman SR, et ál. A Vaccine to prevent herpes zoster and postherpetic neuralgia in older adults. NEngl J Med. 2005;352:2271-2284.

37. Baumrin E, Van Voorhees A, Garg A, et ál. A systematic review of herpes zoster incidence and consensus recommendations on vaccination in adult patients on systemic therapy for psoriasis or psoriatic arthritis: From the Medical Board of the National Psoriasis Foundation. J Am Acad Dermatol. 2019;81:102-110.

38. Disposición 1850 de la Administración Nacional de Medicamentos, Alimentos y Tecnología Médica, Ministerio de Salud de la República Argentina. 27 de marzo de 2013 [en línea]. Disponible en: http://www.anmat.gov.ar/boletin_anmat/marzo_2013/ Dispo_1850-13.pdf [Consulta: enero 2021].

\section{CUESTIONARIO DE EVALUACIÓN}

1) La dosis recomendada del aciclovir por vía oral en los adultos con herpes zóster es:

A. $800 \mathrm{mg} 5$ veces por día.

B. $400 \mathrm{mg} 5$ veces por día.

C. $800 \mathrm{mg} 3$ veces por día.

D. $400 \mathrm{mg} 3$ veces por día.

\section{2) La dosis recomendada del acidovir por vía intravenosa para los pacientes con} herpes zóster es:

A. $8 \mathrm{mg} / \mathrm{kg} / 6$ horas.

B. $10 \mathrm{mg} / \mathrm{kg} / 6$ horas.

C. $10 \mathrm{mg} / \mathrm{kg} / 8$ horas.

D. $15 \mathrm{mg} / \mathrm{kg} / 6$ horas.

3) Los analgésicos recomendados contra el dolor agudo neuropático son:

A. Paracetamol.

B. Paracetamol + opioides.

C. Paracetamol + opioides + pregabalina.

D. AINE.

\section{4) La vacuna Zostavax ${ }^{\circledast}$ :}

A. Contiene una subunidad inactivada del VVZ.

B. Se recomienda su aplicación en adultos inmunocompetentes a partir de los 60 años y en pacientes mayores de 50 años con comorbilidades.

C. Se puede indicar en los pacientes con estados de inmunosupresión primaria 0 adquirida, en aquellos con tuberculosis activa sin tratamiento y en las embarazadas.

D. Se indica en dos dosis, separadas por 2 a 6 meses, por vía intramuscular.

5) Se considera herpes zóster diseminado al compromiso de:

A. Dos o más dermatomas no contiguos.

B. Dos o más dermatomas contiguos, dos o más dermatomas distantes, más de 20 vesículas por fuera del dermatoma inicial o compromiso sistémico visceral. C. Compromiso de un solo dermatoma.

D. Presencia de púrpura y ampollas.

6) En los pacientes menores de 50 años con herpes zóster se recomienda estudiar las enfermedades subyacentes como:

A. VIH.

B. Hepatitis ByC.

\section{Neoplasias de órganos sólidos. \\ D. Neoplasias hematológicas.}

\section{7) No se considera un factor de riesgo para el desarrollo de complicaciones del herpeszóster a:}

A. Edad avanzada, inmunosupresión, presencia de lesiones hemorrágicas o necróticas.

B. Herpes zóster diseminado.

C. Afectación visceral o del SNC, dolor prodrómico o dolor agudo intenso.

D. Embarazo.

\section{8) Se conoce como síndrome de Ramsay-Hunta:}

A. El herpes zóster ótico asociado a parálisis facial periférica aguda y otalgia.

B. El herpes zóster asociado a otalgia grave.

C. La pérdida de la audición asociada a otalgia.

D. El herpes zóster asociado a pérdida de la audición.

9) Con respecto al herpes zóster, marque la opción correcta:

A. Se recomienda el aislamiento de contacto y por gotas de todos los pacientes con la forma diseminada de la enfermedad, sean inmunosuprimidos o inmunocompetentes.

B. El virus de la varicela zóster no es transmisible entre las personas.

C. El uso de valaciclovir no es eficaz en la disminución de la neuralgia posherpética.

D. No se recomienda cubrir las lesiones del herpes zóster.

\section{0) Se sugiere realizar el tratamiento con aciclovir intravenoso en las siguientes situaciones, excepto:}

A. Inmunosuprimidos (cáncer, enfermedades oncohematológicas, VIH, trasplante de médula ósea u órgano sólido, fármacos inmunosupresores). B. Compromiso visceral.

C. Enfermedades cutáneas graves concomitantes como dermatitis atópica y pénfigo vulgar.

D. Edad avanzada.

\section{Respuestas correctas Vol. XXVII, № 1, 2021}

1. D/2.D/3.B/4. B/5.A/6.B/7.B/8.C/9.C/10. D 